\title{
De-standardised pathways to adulthood: European perspectives on informal learning in informal networks
}

\author{
Barbara Stauber
}

Institute for Regional Innovation and Social Research (IRIS)

\section{Andreas Walther}

University of Tübingen. Institute of Educational Sciences

\begin{abstract}
Becoming adult in the context of de-standardised life course transitions means new demands for the young women and men concerned. While those with higher social and cultural capital cope more easily with shaping individualised transitions, those with restricted resources and opportunities are under pressure of adaptation and at risk of exclusion. While de-standardisation can be regarded as a general trend, it takes varying shape across different European transition regimes whereby different regulative, normative and policy contexts of youth transitions are clustered. The article relates to the European YOYO study which has explored new learning demands and new learning strategies of young people in a comparative perspective. An exemplary illustration refers to the way in which young Germans make use of informal learning networks to cope with these demands. This micro perspective is related to the macro perspective by reflecting the scopes of individual agency provided by different transition regimes.
\end{abstract}

Key words: youth transitions, new learning demands, new learning strategies, learning networks.

Resum. Itineraris desestandarditzats a l'edat adulta: la perspectiva europea de l'aprenentatge informal a xarxes informals

Esdevenir adult en el context de les transicions desestandarditzades de la vida comporta noves demandes per part dels joves, els homes i les dones afectats. Mentre que aquells que disposen d'un capital social i cultural més elevat poden modelar més facilment les transicions individualitzades, aquells que no disposen de tants recursos ni oportunitats es troben sota la pressió d'adaptar-se i davant el perill de l'exclusió. Si bé la desestandardització es pot veure com una tendència general, adopta diferents formes en els diferents règims de transició europeus a través dels quals s'agrupen diferents contextos regulatius, normatius i polítics de les transicions juvenils. L'article està relacionat amb l'estudi europeu YOYO, que ha explorat noves demandes d'ensenyament i noves estratègies d'ensenyament dels joves des d'un punt de vista comparatiu. Un exemple il.lustratiu fa referència a com els joves alemanys utilitzen xarxes d'aprenentatge informals per poder fer front a aquestes demandes. Aquesta microperspectiva està relacionada amb la macro perspectiva, ja que reflecteix l'abast de l'agència individual que proporcionen els diferents règims de transició.

Paraules clau: la transició dels joves, noves demandes per a l'aprenentatge, noves estratègies d'aprenentatge, xarxes d'aprenentatge. 


\section{Summary}

Becoming adult in late modernity: from linear to yo-yo transitions

Different contexts of youth transitions across Europe

New learning demands for young people
Learning strategies of young people and prerequisites

Ambivalences: From educational plans towards learning networks

References

With the increasing erosion of female and male standard biographies the topic of life course transitions has gained in relevance. In the framework of institutionalised life courses, transitions from youth to adulthood are foreseen to follow specific trajectories according to educational level and gender. However, if life, as young men and women themselves experience it, does no longer fit to normative institutional assumptions; if transitions occur more frequently, take longer time and are less predictable, they cause more frictions and are experienced more consciously as uncertain and insecure. Inasmuch trajectories can no longer be pursued smoothly they lose their integrative potential for larger and larger groups. This concerns even those with higher educational credentials such as professionals in the ICT sector who, overnight, may experience the devaluation of their skills and qualifications; or young people who do not find opportunities to ensure that their investment into vocational training qualifications pays off. Although structures of inequality are reproduced, institutionalised trajectories in general, reveal increasing risks of social exclusion that for a long time had been restricted to specific trajectories according to gender, social or ethnic origin. However, this trend takes different forms in different European contexts with institutional structures buffering or in contrast increasing respective risks.

This European perspective results from our involvement in the European research network EGRIS (European Group for Integrated Social Research) ${ }^{1}$. Our text combines a general perspective on changes in youth transitions with a comparative perspective on different contexts of youth transitions in Europe on the one hand and a biographical perspective relating to exemplary findings from qualitative research carried out in West Germany on the other. In the first section we outline these broader changes in transitions that can be characterised as de-standardisation of formerly linear status passages towards what in the framework of the EGRIS group has been called "yo-yo» transitions. In

1. EGRIS has been existing since 1993 and has carried out projects and seminars dealing with the implications and contradictions of "Lifelong Learning in Europe», with "Misleading Trajectories» in employment policies for young adults, with the role of Families in Young People's Transitions to the Labour Market as well as the questions what role «Youth Policy and Participation" play in this regard. Other EGRIS partners come from the UK, Spain, Romania, Portugal, the Netherlands, Italy, Ireland, Germany, Bulgaria and Denmark (for more information see www.iris-egris.de/egris). 
the second section we introduce into the different «transition regimes» in which this process of de-standardisation takes place across Europe. In the third section we want to draw on young people's subjective transition experiences and the ways they see and construct themselves as learners by discussing qualitiative empirical data generated in West Germany in the context of a European research project on "Youth Policy and Participation» (YOYO). Special attention is paid to social networks as settings of informal and non-formal learning processes. Finally, we carefully generalize these findings, try to draw some conclusions from them and relate them to the contexts of the different transition regimes for further research and policies addressing the risks in young people's transitions.

We are conscious about shifting from a macro- to a micro-perspective and back; this could be problematic, if conclusions are drawn too narrowly from one level to the other. Instead, we intent that both levels inform each other: in this sense, we have carried out in-depth analysis of interviews on the background of sound context information on structures, present figures and recent policy debates concerning the field of youth transitions. The other way around, we use biographical material in order to inform policies by real biographies, which represent "radical documents of sociality» (Apitzsch, 1990: 13). This means: They are exemplary, they are illustrative, but nevertheless they include a lot of relevant information which should be considered in transition policies which really want to reach their addressees.

\section{Becoming adult in late modernity: from linear to yo-yo transitions}

Traditional sociological concepts conceived life course transitions as linear, directed and irreversible status passages, accompanied by symbolical rites de passage, departing from one life phase in order to arrive at the next one, which in the case of youth transitions would mean to achieve gendered attributes of adulthood, status and recognition (Van Gennep, 1986; Glaser/Strauss, 1971):

[...] a principal (and limiting) feature of most status passages studied implicitly by anthropologists and sociologists is their relatively scheduled character. Those passages are governed by fairly clear rules concerning when the change of status should be made, by whom and by whose agency. There are also prescribed sequences of steps [...] and regularized actions that must be carried out $[\ldots]$ in order that the passage actually be accomplished. (Glaser/Strauss 1971: 3)

Planning, clear rules, linearity, directedness, irreversibility, according to Zygmunt Bauman (1992), constitute key elements of the basic ideology of modernity. It is exactly these assumptions that are less and less accurate under conditions of late modernity: changes in standard life courses increase the emergence of patchwork careers, both for men and for women, including the area of personal relationships. In this context transitions increase, they do 
no longer follow pre-determined patterns and they are more and more reversible due to unemployment, divorce, forced or chosen job change. Such structural changes in life courses - which are referred to as de-standardisation (Walther, Stauber et al., 2002) or even as de-structuring of life courses (Hurrelmann, 2003) — on the side of the individuals always are both chance and risk at the same time. This makes transitions the topic of late modernity related to hopes (with regard to perspectives of social change) and fears (in terms of social disintegration). The individualisation thesis - in a critical perspective- points to the increasing delegation of responsibilities to individuals and to the paradox of individual coping with structural risks. The question of coping with or better: shaping of transitions increasingly becomes decisive for social integration; crossroads of biographical success or failure depending on (unequal) conditions and prerequisites.

What does this mean for young men and women's transitions to work? Individualisation means having to rely on oneself to identify meaningful and viable options as well as to develop the necessary competencies. In fact, young men and women feel alone in such fundamental questions of orientation while distrust and scepticism against institutions like employment services and formal education and training prevail. At the same time they make the discovery that despite the importance of formal qualifications, informal resources and what Field and others have discussed as social capital (Field et al., 2000; Field, 2003), which means: the availability of social connections and network resources, becomes more and more decisive for subjectively successful transitions - also in a new version of youth cultural capital (Pais, 1995; Miles et al., 2002). The boom of start-up companies in the second half of the 1990's for some time even gave the impression as if in the first place, life style, good contacts in the scene, informal networks made the decisive difference.

Young women and men increasingly have to deal with the paradox of forward planning: on the one hand, they are encouraged by all transitional institutions to plan their transitions and careers, while on the other hand, they constantly experience the need for contingency plans which in itself provides evidence for the decreased feasibility to plan transitions: traditional gendered patterns have ceased to provide reliable orientation and are being replaced by a diversity of new demands which often contradict each other and which are not always transparent. This trend towards «fragmented contextualisation» (Mørch, 1999) means that youth no longer coincides only with education but includes experiences of work and unemployment as well; transitions to work interfere with transitions in other aspects of life, such as family relationships and the conditions connected to family support; they have to be reconciled with gendered identity work required to imagine and construct oneself in the present and the future as a man or a woman and therefore are also connected to the sphere of youth culture and life styles. This means that transitions imply constant motion —like a "yo-yo" (EGRIS, 2001; Du Bois-Reymond and López Blasco, 2004): progress towards autonomy in one area may be accompanied by setbacks in others - such as moving back due to lack of resources or sepa- 
ration from a partner. The simultaneity of different demands qualifies the idea of progressive autonomy while competence in dealing with partial autonomy between youth and adulthood becomes more and more necessary. Rather than the notion of «youth» which has been constructed to characterise a linear and direct trajectory towards fully integrated adulthood (also becoming longer and longer through history), we therefore prefer that of «young adults» reflecting that the increased «indirectness» of youth transitions has created new life conditions. Compared to the traditional view of youth -invented in the wake of modernity as the life phase of preparation for work - characterised by formal education leading to adulthood structured by standard employment and social security systems the transitions of young adults more and more extend into less formalised social areas. School and training need to be complemented by lifelong learning which increasingly implies non-formal and informal learning; standard full-time employment is being replaced by flexible and precarious jobs; needs of support which increase due to insecurity and uncertainty no longer are met by the welfare state but by families and other informal networks (Mørch, 2003; López Blasco et al., 2003; Du Bois-Reymond, 2004; Pohl et al., 2004; Biggart and Walther, 2005).

\section{Different contexts of youth transitions across Europe}

If we have introduced the de-standardisation from linear towards yo-yo-transitions as a universal trend this is only a part of the reality. In fact, it takes different forms in different contexts. These differences result from the different socio-economic institutional and cultural frameworks of growing up that have been developed especially since the $18^{\text {th }}$ century. With the notion of transition regimes we refer to the fact that not only the pure structure of education systems but also their relation with other societal sectors such as the labour market or the welfare state and their underlying assumptions create climates of normality informing society and individuals what "youth» is about, what collective demands and what individual aspirations are legitimate (Walther, 2003). A typology of transition regimes can build on the work that has been done with regard to the comparison of welfare regimes (Esping-Andersen, 1990; Gallie and Paugam, 2000), employment systems (Shavit and Muller, 1998), programmes to combat youth unemployment (Furlong and McNeish, 2001; McNeish and Loncle, 2003), gender policies (Pfau-Effinger, 2000) or youth policies (IARD, 2001). Inasmuch youth has started its voyage through modernity in the education system this plays a central role. While Allmendinger (1989) suggests to differentiate education systems according to stratification and standardisation Mørch (2003) takes a historical perspective. He distinguishes the stages of «differentiated qualification" which (especially in the $19^{\text {th }}$ century) allocated different social groups to different schools, «educational differentiation» reproducing inequality according to meritocratic principles which is the case in most contemporary school systems, which at present confront the challenge of «qualified differentiation» which allows for individual educa- 
tion plans or of «labour market orientation» aiming at tying qualifications to economic needs. One result of comparative analysis is that transition regimes include different notions of youth in the sense of dominant expectations towards young people's role in society (Walther, 2003; Walther et al., 2002):

- The liberal transition regime in the Anglo-Saxon countries is best characterised by the notion of individual responsibility which only recently has been reinforced in labour maket policies such as the New Deal in which young people without work face major pressure to enter the workforce. This stands for the fact that youth is regarded as a basically transitory life phase which should be turned into economic independence as soon as possible. The labour market is structured by a high degree of flexibility. While this provides multiple entry options it also implies a high level of insecurity. Correspondingly, although female employment is high, it tends to be of part-time nature and in low-skilled or unskilled service occupations. Despite recent reforms, education and training still can be referred to as «educational differentiation" inasmuch social origin have a high influence on young people's destination. In the context of highly individualising policies young people face considerable risks of social exclusion (Furlong and Cartmel, 1997).

- The universalistic transition regime of the Nordic countries is based on comprehensive education systems in which general and vocational education are largely integrated. Rather than primarily pointing to direct labour market relevance the education system reflects the individualisation of life courses and can be classified as "qualified differentiation». While youth is first of all associated with individual personal development, young people's status is that of "citizens in education». This is reflected by an education allowance for all who are over 18 and still in the education system which contributes to a partial independence from their families. Also, in labour market oriented activation policies, individual choice is rather broad to secure individual motivation. Gendered career opportunities are highly balanced due to the integration of general and vocational education, the broad relevance of the public employment sector and the availability of child care (see also Bechmann Jensen and Mørch-Hejl, 2001; Os and Mørch, 2001).

- In the Mediterranean countries welfare regimes are sub-protective in a double sense. Although the school system is organised in a largely comprehensive way with a majority leaving with post-compulsory qualifications one can speak of a de facto system of «educational differentiation». Due to a lack of reliable training pathways into the labour market, transitions often imply a waiting phase until the mid 30ies with unequal outcomes (current reforms are likely to move the system into the direction of «labour market orientation»). As they are not entitled to any kind of social benefits young men and women depend to a large extent on their families who are referred to as «social amortisator» for the socio-political vacuum. While 
long family dependency stands for the fact that youth does not have a formal status and place in society - but recent research suggests that there are big differences also among Mediterranean countries, from the positive pole of big freedom for young people living with their parents (as seems to characterise the Italian situation) to the quite pessimistic pole of «forced harmony» (as tends to be the situation in Spain) (Biggart, 2005). Higher education is one choice of young people as it provides them a recognised status, despite the fact that relatively few achieve university qualifications and informal work helps to gain a limited amount of economic independence. The familistic welfare regime affects young women especially who have less career opportunities and anticipate responsibility for later family obligations.

- The post-socialist transition regimes at first sight appear rather close to the sub-protective welfare states with public structures being experienced as totally unreliable. Yet, differentiation is needed in a double sense: first, a probably increasingly sub-protective presence is still related to the (socialist) past in which life courses were structured in a mixture of a universalist guarantee of social positions which - in an employment-centred logicwere tied to employment (to which everyone was entitled and respectively obliged). In terms of education, this can be characterised as the shift from a «labour market oriented» system — having lost its reference of state economy - towards «educational differentiation». The second differentiation has to be made with regard to differences between countries like the Czech Republic which can be referred to as «re-institutionalised» and «deinstitutionalised» countries, such as Romania (Wallace, 2002). According to Kovacheva (2001), one particular feature of youth transitions is that life conditions either leap from pre-modern constellations into post-modern fragmented ones, or, are a mixture of both.

- Our perspective is that of the employment-centred regime of continental countries such as Germany, in which a differentiated (and partly highly selective) school system leads into a rigidly standardised and gendered system of vocational training. "Educational differentiation» thus occurs by means of different tracks separating pupils at age ten according to performance and providing only one third with qualifications that qualify for higher education. The dominant task of youth is to socialise for a set occupational and social position - through training. This is reflected through the provision of a two-tiered division of social security, favouring those who have already been in regular training or employment, while others are entitled to stigmatised social assistance. This accounts as well for those who fail to enter regular vocational training. They are referred to as «disadvantaged» from a deficit-oriented perspective and consequently, are channelled into pre-vocational measures, governed by the objective «first of all, they need to learn to know what work means", in other terms: adaptation, reduction of aspiration, holding out. 
In the following we will write from this latter perspective. Although we think that our findings have some general validity, and although the situation of de-standardised transitions is comparable all over Europe, it is important to keep in mind the specific regime context which give de-standardisation a different outlook. With regard to the German transitional system, the speciality has to be considered, that youth in Germany is mostly about being trained (rather than educated) for standard vocational work. Those who fail to enter this route are expected to make up for any deficit by means of compensatory education - or to «cool» out their aspirations and to adapt to the precarious margins of the labour market.

\section{New learning demands for young people}

In the following paragraphs we will discuss some findings of the EGRIS project, «Youth Policy and Participation» (YOYO), which analyses the prerequisites for the motivated and active engagement of young men and women in their transitions to work ${ }^{2}$. This research had a two-pronged approach. On the one hand, in-depth interviews with young people, partly structured according to central themes related to the research objectives, but still open enough to ensure also biographical narratives were undertaken. One group of interviewees was clustered as «disengaged» young people who had withdrawn from the formal transition system for reasons of demotivation. These young people were contacted through agencies operating with a «low threshold approach» where it was more likely to find them as opposed to other training or counselling contexts. Another group was clustered as «trendsetters» because they had taken decisions to construct trajectories partly beyond formal and institutional structures and were quite successful in doing so (see Du Bois-Reymond, 2004). For example, young entrepreneurs, who had dropped out from higher education (although most of them had at least completed post-compulsory school). This comparison was motivated by the assumption that «trendsetters» would share the same distrust as disengaged young people towards formal institutions and therefore could serve as models for transition policies. It has to be said that the distinction between these groups is mainly a heuristic one which had influence on the sampling process while in the findings a variety of intermediate and mixed cases emerged. The interviews centred on subjective transition experiences and included the relationship between formal and informal

2. The project «Youth Policy and Participation. Potentials of participation and informal learning for young people's transitions to the labour market" is funded by the European Commission under the Fifth Framework Programme and is running from 2001 to 2004. The project is coordinated by IRIS, Institute for Regional Innovation and Social Research, Tübingen. Partners involved come from Copenhagen (Denmark), Dresden and Munich (Germany), Coleraine (Northern Ireland/UK), Cork (Ireland), Bologna (Italy), Leiden (Netherlands), Lisbon (Portugal), Bucharest (Romania) and Valencia (Spain). Details and working papers can be downloaded at www.iris-egris.de/yoyo 
contexts of learning and support. On the other hand, case studies have been carried out with agencies that address youth transitions more consciously and explicitly from a perspective of empowerment by active participation -in terms of decision-taking and real influence- and by recognition of informal learning and informal support. In the following we will refer to the West German sample of the study. The case studies have been done with an outreach youth work project (Mobile Youth Work, Stuttgart) providing low threshold counselling and guidance for young people in deprived neighbourhoods - most of them young males with a migration background without neither training or job; and a project providing a regular three year training in dressmaking for young women from ethnic minorities through a holistic supportive approach (La Silhouette, Munich). In total 33 young people were interviewed ( 9 as trendsetters, 24 as disengaged). We will pay particular attention to the extent in which the accounts of the young people give evidence for the hypothesis that formal cultural capital is no longer sufficient but needs to be backed up and/or complemented by «individualised systems of social capital» (Raffo and Reeves, 2000).

What does learning mean in the context of yo-yo transitions? What are the demands young men and women are confronted with? What sort of learning experiences do they participate in and which of them are relevant? What are central prerequisites?

The fundamental demand for young people all over Europe is to learn to cope with yo-yo movements in their own biography in such a way that they become productive, that risks of disappointment and demotivation are limited and balanced by positive experiences. A positive assessment of their own biography enables young people to experience yo-yo transitions as the result of their own agency which in turn motivates for further decisions and steps to be taken. In this regard the dimension of self-efficacy (Bandura, 1997), but also that of self-presentation (Stauber, 2004), become increasingly decisive. And here the structural dimension of learning becomes visible inasmuch of course as the unequal resources of the two groups of interviewees made a difference.

First of all, this can be viewed in terms of orientation. The increasing amount of decisions to be taken poses the demand to know as early as possible about own interests and to realise them especially if the conditions are not totally favourable. All institutions in the transition system do stress this demand but obviously it is difficult to provide appropriate conditions for such basic orientation - at least in the framework of the German transition system. In contrast, many young women and men leave school «without any plan at all» which accounts for the frustrating experiences at the vocational counselling sessions of the employment service, as it is often only the first real experiences with concrete work, training or study that allows for an approach of self-experience and self-reflexivity. Very often these experiences do not take place in formal settings but in the informal context for example of youth culture. 
The differences in the availability of social capital (Field, 2003) can be shown by the example of Jonas (interviewed as «trendsetter») who was still in school when he started his own computer business:

Of course I have the advantage that through my parents I have lots of contacts to business people; also in top level positions. If I would like to orientate towards this or that direction I could call them «I have this and that idea [...] tell me how it went in your case». $\left(\right.$ Jonas $\left.^{3}, 21\right)$

In such cases normally the point of personal relevance is not in question. These young women and men profit from an important framework already in place and in some cases one which they have created themselves as active parts of youth cultural scenes. For them the long-term viability of such an important framework is less important than the fact that bridges are built between personal orientation knowledge and first steps in professional life.

In the case of those young people who had failed to enter regular training and who have disengaged with formal institutions, orientation from the beginning also implies the need to deal with ascriptions of failure and demands of adaptation, often related to gender or ethnicity. For young migrants the relation between being a "foreigner" and restricted opportunities is revealed in school. In the worst case this process is individualised and carries the risk of accepting ascriptions as "disadvantaged» and therefore reducing aspirations and motivation. The young males interviewed in the context of Mobile Youth Work, Stuttgart, rationalised the withdrawal from the formal system with regard to age related behaviour: "At that time I just fucked it all up» (Özkan, 19).

With such statements they secure a gender specific and youth culturally embedded interpretation of restricted chances in which individualised ascriptions serve to protect the own identity against victimisation. In the best case this is dealt with collectively, as in the Munich training project La Silhouette. Through profund reflection and group building processes these young women have developed a critical consciousness against the myth of gender equality and of successful integration: they know that due to being young women and migrants they are systematically and structurally disadvantaged on the labour market. They realise the contradictory nature of the German transition system which despite the strong selection process at the transition stage from school to training, defends the norm of regular training also for the «transition losers».

You get pressure: you must, must, must [...] training, training, training, training. Without training you will never make it. And nobody tells you about other ways. (Jelena, 21)

3. All names changed. 
And they are very much aware of the gendered segmentation of the training system:

In basic secondary school you — the girls — are offered occupations such as hair-dresser, shop assistant, not even nursery school teacher professions, [...] which I never wanted to do. (Mona, 17)

A second key demand can be identified in the need of adaptation. However, in this perspective adaptation rather than as giving way to institutional power or the scarcity of opportunities, in terms of cutting off what does not fit to actual opportunities, should be understood in a sense of biographical reflexivity - biographicity (Alheit and Dausien, 2000). This first implies that young women and men know what they want and are aware of their own strengths and weaknesses. Second, and even more important, it means to relate their needs and capabilities to the social environment, such as the labour market, to assess what fits and what will not fit, to accept compromise, as long as it is a means of reaching a meaningful goal and does not imply giving up these goals. This implies to reflect on how such goals can be integrated into the own life plan. Does a compromise represent a short deviation or does it contradict the own plan? Can it be presented and justified in the relevant social context of family or peers? This demand relates to a specific mix of informal and formal learning. In this regard the former is required to cope with the demands of the latter; in terms of a form of "motivation management» either to stay the course or to drop out in order to start something new for which motivation is higher. It is important not to reduce adaptation oriented learning to a simple "going with the flow» (although this of course is always implied to a major or minor degree as well) but to regard it as result of a process of negotiation which occurs in a more or less reflective way.

This demand includes that individuals mediate between their own skills and competencies and those required by the labour market. Due to the fact that in Germany skills are still fixed to certificates as keys for labour market entry this demand is relatively hidden. Nevertheless, it becomes more and more important to relate possibilities and opportunities with both the own life plan and the formal and informal demands of the labour market.

Such assessment is found in the accounts of so-called «trendsetters» in both directions:

Max who has started a music career describes how —instead of dropping out school due to de-motivation - he managed to follow the encouragement by some supportive teachers who understood his enthusiasm in music:

Some younger [teachers], for example, [...] they did understand this. They told me: Max, what's going on? Pull yourself together once more! After high school certificate you can do what you like. (Max, 20)

Carla in contrast, in assessing her problems in university comes to the conclusion to change direction (yet at a stage in her career where this has less 
negative consequences as going back to university is less problematic than making up with missed school qualifications). She drops out and now successfully manages a trendy bar:

I simply didn't like learning, sitting and doing nothing else than looking at my books. This simply wasn't my thing. I had very productive hours in all other kinds of things in periods when I was supposed to prepare an exam or something. I'd clean up the flat all over, but these moments make you think what's the point in all this studying. (Carla, 24)

Young people with low qualifications indirectly use their peers to test individually and collectively to what degree compromises are acceptable, such as Martin who is happy to have found an apprenticeship in road construction - definitely not his first choice:

You know, we were sitting with the crowd talking and I said, «I've got an apprenticeship». The others asked, «in what?». Me, «road construction». And them, "Oh shit, that sounds bad». And I said: "Guys, that's what I thought as well but it's not that bad. [...] Your really need your brains». (Martin, 19)

Prerequisite for such negotiation on meaning, acceptance and biographical fit is to identify and to use appropriate opportunities — in school, with siblings or friends.

Another, often hidden demand of learning relates to networking. The more the ideology is: everyone is the architect of his or her own fortune, the more important it is to relate to other persons. Apparently those young people who have taken the risk of leaving the conventional trajectories for a more individual and autonomous life plan have understood this quite well. Either because they had to compensate for the lack of resources available through social origin or because they found that these resources were not sufficient for the construction of a satisfying and successful life, therefore, they depend on individual networking to develop and activate them. An example is Carla, the bar manager:

Of course, you know plenty of people from the scene and you have to be very open minded and straight forward. [...] And to a certain extent you also have to be bold. (Carla, 24)

As a result of this active attitude Carla makes use of socially and spatially wide-spread network relationships which she has built in the course of her career of occasional jobs as much as of her private and youth cultural development. The network relationships differ considerably in terms of quality -but all are equally important. There are strategic relationships with people who - in a certain sense - were in the right place at the right moment providing support in the appropriate way (be it material, be it professional advice); there are relationships with persons who are «just there» through familial or emotional bonds; or people who follow the same ideas and projects and are 
available as cooperation partners (as in her case her boyfriend but also her peers). There are relationships which are characterised by expectations of reciprocity while others are shaped more strategically. All these people from the individual perspective are considered as «significant others" (Mead, 1934). The heterogeneity of these network relationships appears to be an important criterion for their functionality in transitions under late modern conditions because of the diversity of emerging needs of support.

The demand of learning related to social networks therefore consists of five dimensions: first, to identify social networks as a resource; second, to be able to activate and to use them; third to be open for the heterogeneity of networks; fourth, to reflect the informal processes in which networks emerge, develop - or collapse. And fifth, it is fundamental that young men and women reflect and relativate the myth of having to make it alone (and of being capable to do so) resulting from individualisation. Carla stresses that with regard to the style of the bar she relied on her friends whom she recognises as youth cultural experts:

It is so important to discuss with a lot of people. [...] Now and then through the process of restructuring people whom you knew dropped in [...] and then they make suggestions how to improve it [...] We had two or three meetings with friends who really go out a lot [...] to reflect on the target group the type of music, the main direction of the layout and so on. In these things you really have to be open for what others tell you. (Carla, 24)

As regards the young people with lower qualifications, most of them living in less priviledged areas, having a migration background and lacking relevant family support, they do not have any relevant network relationships, as was the case with many of the young migrant women in the La Silhouette project in Munich, or their networks are much more homogeneous as in the case of the young people addressed by Mobile Youth Work in Stuttgart. Young males especially often use their peers primarily to confirm each other in their orientation to value respect (from employers or employment service officers) higher than career related progress at any cost and to justify decisions to drop out or to refuse to active job search. The projects starts from their attempts either to build new networks or to extend the grown life-world related networks towards other social sectors and especially towards career relevant actors.

The concept of Mobile Youth Work considers the life-world related networks as a starting point for their work. Peer groups of young people are central to its approach. The social structures, youthful patterns of behaviour and resources given within them are taken up in what is called "gang-oriented" work. The young users of the service grow «organically» into these structures and do not consider this a conscious choice of social relationships:

[How would you describe the contact you have with the people here where you come to write your job applications?] [...] among us this is simply normal, it's passed on from generation to generation. (Yildirim, 19) 
In the Munich project La Silhouette the young migrant women have found a place where their critical attitude towards societal demands are understood and the energies that flow from them are used productively; in their creative work with fashion and design, the reflection of gender and culture is included. Fashion reveals itself to be an excellent means for negotiating gender and negotiating culture.

The first time I came here, I was so excited, because for the first time I seriously applied for a place and I for the first time really wanted it. Yes. [...] And they integrated me so well. I was on a one-week placement, and I sewed a bag. I did that so well, I was so fascinated about this bag, and about myself [...] this "being creative». And the whole place, which gave me the impression; this is not so hard, this is a place where you can talk and be open. (Jelena, 21)

Formal education provided by the project in terms of a regular training qualification is to an extent informalised (or better: non-formalised). The project provides the young women a home, a group environment that offers both safety and recognition but also collective reflection, flat hierarchies and far reaching participation rights in terms of organisational related questions but also with regard to the shape of working, learning and education.

\section{Learning strategies of young people and prerequisites}

Out of these findings and the results of other case studies in the context of the YOYO-project we can carefully generalize some characteristics of learning processes and how they can be facilitated: Learning to actively cope with demands: adaptive learning in the sense of "managing» one's motivation, acquiring personal orientation knowledge in terms of getting to know the own interests, learning of active networking, are learning demands which young women and men face and which depend on individual contexts of learning and on social networks; apart from cultural capital, «individual systems of social capital» also gain importance (Raffo and Reeves, 2000, p. 154). From a policyoriented perspective this means to ask whether social networks are able to provide connections to other social contexts, to open gates to the labour market or doors into institutions in order to create new possibilities. This refers to the structural level. Such bridges are important to get new information, support or contacts and they are characterised by weaker obligations of reciprocity and higher strategic utility (the strength of weak ties; Granovetter, 1973).

On the other side, young people need emotionally charged relationships that provide emotional support, such as, a sense of safety, comfort, and encouragement. In the context of highly individualised transitions these are even more important complements to the former. This means that an intersubjective dimension of intervention has to provide young men and women with a basic feeling of belonging (Wenger, 1998) through which they are encouraged to build, to develop and to use network relationships. Experiences of demo- 
tivation, in contrast, go along with social isolation and cutting off of relationships which lie beyond the closer life-world. Trust in the meaning of group membership and relationships first need to be reinforced, positive experiences have to be made before network relationships are taken up again.

Weak as well as strong ties are needed — bridging as well as bonding social capital. Therefore family members remain important while at the same time other adult key persons (including professional ones) gain as much relevance as peers and youth cultural systems of reference. Very often network relationships do not serve only one purpose but several ones (cf. Nestmann, 2001).

Arrangements in which network competencies are learned obviously are crucial as social capital only is activated and utilised through interaction (Keupp et al., 1999; Field, 2003). An active attitude therefore seems an indispensable tool if one is going to use, develop or build social capital. This refers to - possibly very subtle - differences and divisions in the acquisition and possession of such a competence: while some had the opportunity to learn how to interact with significant others (see above) and to experience its value, others did not, or their interactions never extended over the borders of their social milieus. However, the so-called "trendsetters» despite having the advantage of favourable starting conditions, also need to stay active to maintain their successful level of networking. Of course, if they cannot maintain a successful level of networking they face considerably lower risks of exclusion.

An important prerequisite of network competence is a self-concept of neither over- nor underestimation, which includes both the awareness of dependency and the confidence into self-efficacy (Bandura, 1997). This is a latent gender issue inasmuch as the consciousness of dependency is not a core element of male socialisation (Böhnisch, 2003). The emergence of new images of strong and self-conscious "girlies» tends to extend this problem also to the female side (Stauber, 1999). To present and expose oneself as dependent and in need of more and more support is a (subjective) risk which points to the relevance of socioeconomically as well as socioculturally conceded spaces and times of experience.

We have shown that it is heterogeneous network relationships that make the difference. Potentially formal networks are as important as the informal ones, families as much as peers, situational ones as much as the actively chosen (Walther et al., 2005), those emerging from life-world contexts as much as the professionally arranged. In this regard, network competence means to identify the relative importance of these different relationships, to identify situations in which it is worth while to overcome an initial shyness with regard to the use of professional support and to integrate it into the subjectively available network. Once again, better starting conditions seem to allow for a more relaxed and strategic relationship attitude towards institutions as the consciousness of own resources and possibilities represents a counterweight against institutional imperatives, even more so in the context of increasingly dominating activation and workfare approaches of «either you accept our offer or we cut your benefits». In contrast, those who already have made discouraging 
experiences with institutions have to overcome the greatest obstacles to reengage in supportive relationships.

The learning of such competencies necessarily occurs informally, «by doing», not through instruction or training - either as a side-effect of everyday life or as the result of intentional but non-formal education. In terms of intervention this means to accept that "learning cannot be designed, [...] only be designed for» (Wenger, 1998, p. 249). The character of learning "by doing» necessarily implies that the acquisition of network competencies is restricted to the structural limits of the respective network. The more a network restricts itself to its original milieu, the less strategic — in the sense of transversalnetwork competencies can be developed.

\section{Ambivalences: From educational plans towards learning networks}

We have started from the observation that youth, established as the life phase individuals spend in education, has not only been prolonged but that its connection to the adult status and life phase has become more indirect and destandardised. By case-study analysis in ten European regions (of which —in the framework of this article - we only could give some insights into one) a lot could be learned about how young women and men actively deal with destandardisation. And a lot could be learned about what they need - under different systemic conditions - in order to maintain a pro-active attitude towards learning. One could say, that on the systemic and on the subjective level there is a similar topic to be dealt with: Inasmuch constellations of postFordist flexibilisation and late modern fragmentation and individualisation make planning more difficult, both state and individuals have started to react. On the side of most individuals there is the tendency to accumulate education credentials in order to confront the educational inflation and reduce the risks of having made wrong educational decisions. However, there is also a continuously high rate of drop-outs at different levels of the education and training system - and indeed: we also have found them in the group we have interviewed as "trendsetters». While some decades ago it would have been the case that to enter the labour market would not necessarily have required postcompulsory education but - especially in less regulated labour markets like the British one- careers also could be formed «on the job», nowadays it either reflects the fact that young people realise they have taken a wrong direction or that young people do no longer believe in their chances to secure a meaningful career through education. We have shown in the section above that across accumulating or disengaging from education young people also have changed their relationship towards the formal system: they directly or indirectly compare and relate it to informal and non-formal contexts. They either try to secure, to match or to replace cultural capital with social capital. If we confront our micro-sociological data with the macro-level of social policies, we find that on the side of state policies there is the trend towards individualised learning careers through the rhetoric and policies of lifelong learning. But here 
we find again considerable differences between the scope the different transition regimes have in order to take into consideration what we have found as relevant with regard to learning and coping with de-standardised transitions. In some cases educational plans are opened and flexible enough to be reconciled with learning networks, in others, educational plans are defended by re-standardisation:

- The employment-centred regime seems to have the biggest difficulties in modernising education and training. The consequences of a highly formalised link between education and training and the labour market are most visible in Germany where the upgrading of qualifications is inhibited by the selective structure of the education system. Furthermore, individualised training pathways do not fit into the standardised system of apprenticeship training. Rather than opening these systems, policies aim at re-standardisation by increasing training capacities (which however is counteracted by economic recession). As a consequence individuals have to cope individually with this increasing mismatch: many drop out from training, even more complete a first training course or study only to start a next one, thus compensating with the lack of flexibility within the system; or they are confronted with increasingly repressive instruments of labour market policies by which they are made self-responsible for their failure to get the «right» education. The perspectives of investing social capital appear to be restricted: while those with higher qualifications may profit from increased opportunities, those with average or lower qualifications mainly need it to survive in the selective system.

- The liberal transition regime shows an increase and a diversification of post-compulsory education and training towards a highly «flexible space» as regards inputs, pathways and outcomes (Raffe et al., 1998) with multiple entrance and exit options. This is reflected by the rising numbers of students in post-compulsory and higher education. At the same time individuals are made responsible for the outcomes of their decisions. Progress towards a system of «qualified differentiation» is counteracted by access to necessary resources to succeed being decreased and made conditional. In this context, social capital is necessary to successfully profit from the increased opportunities (Field and Spence, 1999).

- The sub-protective regime and the post-socialist regimes appear to be split between the attempt to catch up with what is referred to as an institutional modernisation deficit. Especially with regard to the system of vocational education and training as they try to reconnect education and training outcomes with the human capital need of the economy - the trend is towards a «labour market oriented» education system. At the same time however, individuals start to create their own careers by either completing their portfolios through engagement with non-governmental training providers or by actively bridging the gap between education and employment. They engage in voluntary work in the Third Sector or they take the risk of self- 
employment by which social capital is used as a way out of the traps produced by the formal system (which at the same time is only possible due to the structural deficits and the weakness of the formal system).

- The countries clustered in the universalistic regime continue to individualise and flexibilise education and training in a comprehensive system of «qualified differentiation». It is a central feature that material resources and other requirements are catered for and facilitated (for example, counselling aimed at developing intrinsic motivation). Apart from that formal education and training are being «informalised» and inasmuch peer education is systematically applied, building of social capital is also an objective of formal education (although there are also setbacks due to political will like the closure of the Danish Open Youth Education). This results in a combination of the highest rates of post-compulsory and higher education participation while young people in the Nordic countries enter the labour market earlier than in other parts of Europe (cf. IARD, 2001).

It is obvious that different transition regimes provide different opportunities for facilitating what has been found as relevant for learning under changed conditions. They to a different extent have taken the de-standardisation of transitions into account. Across structural differences however it can be said that structures of social inequality along the traditional categories of class, gender and ethnicity still are effective, although perhaps in a more individualised way, transmitted through individual decisions and individual systems of social capital rather than through collective patterns of socialisation. If we look for ways for compensating for these uncertainties and inequalities we find that mainly the states of the universalistic regimes aim at restructuring their systems accordingly by making them accessible, meaningful and relevant (EGRIS, 2002). This means that if at all the equation of "youth = education» is still valid, it is in the Nordic countries. Both policy reform and pedagogical intervention include the objective to contribute to the formation of social capital. In the other countries this is largely restricted to compensatory measures for those labelled as «disadvantaged youth» which often is segregated from the regular system of education and training and runs the risk of creating "container» projects without any biographical perspective (Mørch, 1996). Nevertheless, our analysis can provide insights into prerequisites of arrangements that facilitate learning networks in which individuals reflect on their own interests and needs, on external demands (especially those of the labour market) and engage in developing the skills and competencies which are necessary for meaningful and successful careers.

Dynamic transition processes need dynamic forms of support that by form and content correspond to the yo-yo movements of growing up. The analysis proves that networks more and more are an indispensable prerequisite for coping with biographical transitions in a meaningful way because they provide support more flexibly and informally. While such networks are heterogeneous and tend to reproduce social inequality they obviously are a relevant starting 
point for empowerment oriented policies. This goes along with recent shifts in socialisation theory from traditional concepts of institutionally bound socialisation towards self-socialisation (Heinz, 2002) or biographical self-organisation (Hurrelmann, 2003). Informal networks obviously play a prominent role in theoretical frameworks in which the relationship between biographical narration and actual experience and agency can be reconstructed under consideration of resources and contexts. Socialisation theory refers to individual learning processes but also to the societal recognition of such learning processes. However, the extent in which formal education can no longer guarantee this recognition in terms of complete social citizenship, socialisation is individualised - as in the concept of the lifelong learner. The acceptance of a selfconcept as lifelong learner however also corresponds to responsibility and control which has been delegated to and internalised more and more by the individuals; probably the most accentuated form of individualisation in a neoliberal context. The decisive difference between such policy discourses and an activity theoretical concept is whether they principally consider individuals as active learners (and ask for the conditions under which they are able (or enabled) to learn) or whether individuals are demanded to learn regardless of the conditions under which this occurs.

Learning networks rather than education and training schemes: the network perspective, and this has been illuminated by in-depth analysis of our case-study-projects, becomes a key issue of any intervention in youth transitions which does not address the life-worlds and milieus of its clientèle as deficient, but as social practice which needs to be extended by functional equivalents such as opportunity structures for engagement (Böhnisch, 1994, p. 223; cf. Chisholm, 1999; Nestmann, 2001). Such social practice needs to be recognised in its bonding functions and be extended - rather than functionalised. Starting from their original milieu and transcending their borders, networks can activate social capital; build connecting bridges to other milieus, scenes, life-worlds and systems to open new opportunities. Intervention oriented towards such a concept of support requires embedding in Integrated Transition Policies (Walther, Stauber et al., 2002; López Blasco et al., 2003) that addresses structural prerequisites of successful transitions from the subjective perspective of individual young men and women in all their difference rather than from the institutional one. In this regard, late modernity can be interpreted not only as the shift from rigid institutions towards flexible networks (Castells, 2000) but also as the challenge to accept the limited scope of intentional education and to acknowledge what young women and men themselves find important in order to be able to learn.

\section{References}

Alheit, P.; Dausien, B. (2000). «Biographicity as a basic resource of lifelong learning». In AlHeIT, P. (ed.). Lifelong Learning Inside and Outside of Schools. Roskilde: Roskilde University, Universität Bremen and University of Leeds, p. 400-422. 
APITZSCH, Ursula (1990). «Lernbiographien zwischen den Kulturen». In English: "Learning biographies between the cultures». Paper given on the $12^{\text {th }}$ Conference of the German Educational Resesarch Association. Frankfurt a.M.

Allmendinger, J. (1989). "Educational systems and labour market outcomes». European Sociological Review, vol. 5, no 3, p. 231-250.

BandurA, A. (1997). Self-Efficacy: The Exercise of Control. New York: W.H. Freeman. BAUMAN, Z. (1992). Intimations of Postmodernity. London: Routledge.

Bechmann Jensen, T.; Mørch-HejL, G. (2001). Yoyo: Youth transitions, youth policy and participation. National Report from Denmark. University of Copenhagen: Working Paper.

BIgGaRT, A. (and EGRIS) (2005). Families and Transitions in Europe. Final Scientific Report of the research project FATE. Coleraine: University of Ulster.

BiggarT, A.; Walther, A. (2005). «Young Adults' Yo-Yo Transitions: Struggling for Support between Family and State in Comparative Perspective». In LECCARDI, C.; Ruspini, E. (Hrsg.). A New Youth? Young People, Generations and Family Life. Aldershot: Ashgate, forthcoming.

BÖHNISCH, L. (1994). Gespaltene Normalität. Lebensbewältigung und Sozialpädagogik an den Grenzen der Wohlfahrtsgesellschaft. In English: Split normality. Weinheim; München: Juventa.

- (2003). Entgrenzte Männlichkeit. Verstörungen und Formierungen des Mannseins im gesellschaftlichen Übergang. In English: De-limitations of masculinity. Opladen: Leske+Budrich.

Castells, M. (2000). The Rise of the Network Society. Blackwell.

Chisholm, L. (1999). «From Systems to Networks: The Reconstruction of Youth Transitions in Europe». In HeInZ, W.R. (ed.). From Education to Work: CrossNational Perspectives. Cambridge: Cambridge University Press, p. 298-319.

Du BoIs-ReYMOND, M. (2004). «Youth - Learning - Europe: a ménage à trois?». YOUNG, vol. 12, no. 3, p. 187-205.

Du Bois-ReYmond, M.; LÓPEZ BlasCo, Andreu (2004). «Transiciones tipo yo-yo y trajectorias fallidas: hacia las políticas integradas de transición para los jóvenes europeos». Revista de Estudios de Juventud, no. 65: «Politicas de Juventud en Europa», p. 11-29.

EGRIS (European Group of InTEgrated Social Research) (2001). «Misleading Trajectories: Transition Dilemmas of Young Adults in Europe». Journal of Youth Studies, vol. 4, no. 1, p. 101-118.

Esping-Andersen, G. (1990). The Three Worlds of Welfare Capitalism. Cambridge: Polity Press.

FIELD, J. (2003). Social Capital. London: Routledge.

Field, J.; SCHUller, T.; BARON, S. (2000). «Social Capital and Human Capital Revisited». In BARON, S.; Field, J.; SCHUlleR, T. (eds.). Social Capital: critical perspectives. Oxford: University Press, p. 243-263.

Furlong, A.; Cartmel, F. (1997). Young People and Social Change. Buckingham: Open University Press.

Furlong, A.; MCNeISH, W. (eds.) (2001). Integration through training? Comparing the effectiveness of strategies to promote the integration of unemployed young people in the aftermath of 1997 Luxembourg Summit. Glasgow: University of Glasgow/European Commission.

Gallie, D.; Paugam, S. (eds.) (2000). Welfare Regimes and the Experience of Unemployment in Europe. Oxford: Oxford University Press. 
GeNNEP, van, A. (1986). Übergangsriten (Les rites de passage). Frankfurt a.M./New York.

Glaser, J.B.; Strauss, A. (1971). Status Passage: A Formal Theory. Chicago: AldineAtherlon.

GranovetTer, M. (1973). «The Strength of Weak Ties». American Journal of Sociology, vol. 78, no. 6, p. 1360-1380.

HeINZ, W.R. (2002). «Self-socialisation and Post-traditional Society». In SETTERSTEN, R.; OwENS, T.J. (eds.). New Frontiers of Socialisation. Oxford: Elsevier Science, p. 41-64.

HurRelmanN, K. (2003). «Der entstrukturierte Lebenslauf. Die Auswirkungen der Expansion der Jugendphase». In English: «The de-standardised life-course. Effects of the expansion of youth phase». Zeitschrift für Soziologie der Erziehung und Sozialisation, 23, (2), p. 115-126.

IARD (2001). Study on the State of Young People and Youth Policy in Europe. Milano: IARD.

Keupp, H. et al. (1999). Identitätskonstruktionen. Das Patchwork der Identitäten in der Spätmoderne. In English: Constructions of identity. Reinbek: Rowohlt.

Kovacheva, S. (2001). "Flexibilisation of Youth Transitions in Central and Eastern Europe». YOUNG, vol. 9, no. 1, p. 41-60.

LOPeZ-BlasCo, A.; MCNeish, W.; Walther, A. (eds.) (2003). Young people and contradictions of inclusion: Towards Integrated Transition Policies in Europe. Bristol: Policy Press.

McNeISH, W.; Loncle, P. (2003). «Young people and contradictions of inclusion». In López-Blasco, A.; MCNeish, W.; WalTher, A. (eds.) (2003). Young people and contradictions of inclusion. Towards Integrated Transition Policies in Europe. Bristol: Policy Press, p. 105-126. In Spanish: «Politica pública y desempleo juvenil en la Unión Europea». De Juventud, no. 65 (2004), p. 65-83.

Mead, G.-H. (1934). Mind, Self, Society. London: University of Chicago Press.

Miles, S.; Pohl, A.; Stauber, B.; Walther, A.; Banha, R.; Gomes, M. (2002). Communities of Youth. Cultural Practice and Informal Learning. Aldershot: Ashgate. Mørсh, S. (1999). «Informal Learning and Social Contexts: The Case of Peer Education». In Walther, A.; STAUBER, B. (eds.). Lifelong Learning in Europe. Vol. II: Differences and Divisions. Tübingen: Neuling, p. 145-165.

MørCH, S. (2003). «Youth and Education». YOUNG, vol. 11, no. 2, p. $49-73$.

NeSTMAnN, F. (2001). Soziale Netzwerke - Soziale Unterstützung. In English: «Social Networks - Social Support». In OTTO, H.-U.; ThiersCH, H. (eds.) (2001). Handbuch Sozialarbeit - Sozialpädagogik. Neuwied; Kriftel: Luchterhand, p. 16841692.

PAIS, J. M. (1995). «Growing up on the EC Periphery: Portugal». In CHISHOLM, L.; BÜChner, P.; KRÜGer, H.-H.; Du BoIs-Reymonds, M. (eds.). Growing up in Europe. Berlin and New York: De Gruyter, p. 195-208.

Pfau-EfFinger, B. (2000). "Gender Culture and Social Change in the European Context». In Duncan, S.S.; Pfau-Effinger, B. (eds.). Gender, Economy and Culture in the European Union. London/New York: Routledge, p. 262-276.

RafFo, C.; ReEves, M. (2000). "Youth transitions and social exclusion - developments in social capital theory». Journal of Youth Studies, 3 (2), p. 127-146.

Shavit, Y.; Muller, W. (eds.) (1998). From School to Work. A Comparative Study of Educational Qualifications and Occupational Destination. Oxford: Oxford University Press. 
Stauber, B. (1999). «Starke Mädchen - Kein Problem?». In English: «Strong girls no problem?»). Beiträge zur feministischen Theorie und Praxis, vol. 22, no. 51, p. 53-64.

- (2004). Junge Frauen und Männer in Jugendkulturen:- Selbstinszenierungen und Handlungspotentiale. In English: Young men and women in youth cultures: Potentials of agency through self-presentation. Opladen: Leske+Budrich.

WALLACE, C. (2002). «Opening and closing borders: migration and mobility in EastCentral Europe». Journal of Ethnic and Migration Studies, vol. 28, no. 4, p. 603-625.

Walther, A. (2003). Choices and Voices at Work: Spaces for Young People's Life-plans in European Transition Regimes, Paper for the $8^{\text {th }}$ Nordic Youth Research Symposium 2003 «Youth - Voice and Noise». Roskilde.

Walther, A.; StAuber, B.; POHL, A. (2005). «Informal networks in youth transitions in West-Germany: biographical resource or reproduction of social inequality?». Journal of Youth Studies, vol. 8, no. 2, p. 221-240.

Walther, A.; Pohl, A.; Stauber, B.; Hayes, A. et al. (2005). Youth Policy and Participation. Potentials of participation and informal learning in young people's transitions to the labour market. A comparative analysis in 10 European regions. http://improvingser.jrc.it/default/page.gx?_app.page=entity.html\&_app.action=entity \&_entity.object=TSER----00000000000014EE\&_entity.name=Report

Walther, A.; Stauber, B.; Biggart, A.; Du Bois-Reymond, M.; Furlong, A.; LÓPEZ BlasCO, A.; MøRCH, S.; PAIS, J.M. (2002). Misleading Trajectories. Integration Policies for Young Adults in Europe? Opladen: Leske and Budrich.

Wenger, E. (1998). Communities of Practice. Learning, meaning, and identity. Cambridge: Cambridge University Press.

Barbara Stauber is a Senior Researcher at the Institute for Regional Innovation and Social Research (IRIS), Tübingen (Germany), and at the Tübingen Institute für Gender Studies (TIFS). Her research areas are gender and generation relationships, youth cultures and transition research. E-mail: barbara.stauber@iris-egris.de

Andreas Walther works at the Institute of Educational Sciences at the University of Tübingen, and is a Senior Researcher at the Institute for Regional Innovation and Social Research (IRIS), Tübingen (Germany). His research themes are young people's transitions to work and adulthood and comparative studies on welfare, youth and transition policies. E-mail: andreas.walther@iris-egris.de 